\title{
How best to diagnose urinary tract infection in preschool children in primary care?
}

\author{
Alastair D Hay reader in primary healthcare ${ }^{1}$, Penny Whiting senior research fellow ${ }^{2}$, Christopher \\ C Butler professor of primary care medicine ${ }^{3}$
}

${ }^{1}$ Academic Unit of Primary Health Care, NIHR National School for Primary Care Research, School of Social and Community Medicine, University of Bristol, Bristol BS8 2PS, UK; ${ }^{2}$ School of Social and Community Medicine, University of Bristol, Bristol, UK; ${ }^{3}$ Department of Primary Care and Public Health, School of Medicine, Cardiff University, Cardiff, UK

Accurate and timely diagnosis of urinary tract infection (UTI) in young children presenting to primary care is important because appropriate treatment may alleviate suffering and help prevent long term sequelae such as renal scarring, poor renal growth, recurrent pyelonephritis, impaired glomerular function, hypertension, end stage renal disease, and pre-eclampsia. ${ }^{12}$ The prevalence of renal scarring in the general population is unknown, but a systematic review of studies, largely conducted in secondary care, showed $15 \%$ of children with an initial episode of UTI had evidence of renal scarring on follow-up dimercaptosuccinic acid (DMSA) scanning, and there was an

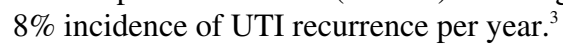

Among consultations for illness episodes in children aged under 5 years in the UK, approximately $40 \%$ comprise infectious diseases and respiratory episodes, while about $10 \%$ of presentations comprise non-specific symptoms. Thus identifying which children have a significant UTI (which often also presents with non-specific symptoms) is a key challenge for primary care clinicians.

The diagnosis is further hampered because young children cannot clearly articulate symptoms; when children wear nappies, parents are not aware of the classic dysuria and frequency symptoms as experienced by adults; and obtaining an adequate urine sample can be frustrating, time consuming, and costly.

The precise prevalence of UTI among all acutely unwell children presenting to primary care is unclear. One systematic review of 10 studies, eight of which were conducted in hospital emergency departments, one in US paediatricians' offices, and one in an army medical centre, estimated UTI prevalence at 7\%. ${ }^{4}$ A large Australian emergency department study published in 2010 found a prevalence of $3.4 \%$ in children presenting with a febrile illness. ${ }^{5}$ We identified only one small exploratory study conducted in general practitioner/family physician practices, which found a prevalence of $4 \%{ }^{6}$

It is not surprising then that the diagnosis of UTI is often delayed and may be missed in up to $50 \%$ of children presenting to primary care, ${ }^{7}$ sometimes due to symptoms being incorrectly attributed to other causes (such as otitis media). The pressure to reduce antibiotic prescribing may reduce the serendipitous treatment of undiagnosed UTI and the consequent prevention of renal sequelae, making accurate diagnosis now even more important than ever.

\section{What is the evidence of the uncertainty?}

The 2007 guidelines on the diagnosis, treatment, and long term management of UTI in children by the National Institute for Health and Clinical Excellence (NICE) ${ }^{8}$ concluded, after a systematic review, that there is uncertainty regarding the following questions on the diagnosis of UTI in children aged less than 5 years in primary care:

1) What is the accuracy of clinical symptoms and signs?

2) What is the accuracy of the combination of nitrite and leucocyte esterase (LE) dipstick test?

3) How do nappy pad or urine bag sample contamination rates compare to supra-pubic aspiration (SPA) or catheter samples?

To address these uncertainties, we considered relevant studies from our 2006 Health Technology Assessment (HTA) funded systematic review of tests for diagnosing UTI in children, ${ }^{9}$ the NICE guidelines, ${ }^{8}$ and a systematic literature search of Medline from 2002 (the end date of the HTA review searches) to April 2011. We used a sensitive search strategy combining terms related to UTI with terms relating to "clinical signs and symptoms," "dipstick testing," or "urine sampling," to identify 
studies published since these reports. We included primary studies or systematic reviews that addressed one of the above questions, used urine culture as the reference standard, enrolled children aged 5 years or less, and were conducted in a primary care or emergency department setting in the Western world.

\section{Clinical symptoms and signs}

We found one systematic review ${ }^{10}$ that included eight primary studies in children aged less than 5 years $(n=7892)$ and three additional primary studies $(\mathrm{n}=17462)$ that fulfilled our inclusion criteria. ${ }^{511}{ }^{12}$ Of these 11 studies, nine were conducted in hospital emergency departments, and two in paediatricians' offices; none was conducted in general practices or family physician practices. The web table shows positive and negative likelihood ratios for each clinical sign and symptom together with estimates of the post-test probability of disease for the presence and absence of each symptom based on the prevalences (pre-test probabilities) of UTI of $4 \%$ seen in the study by O'Brien ${ }^{6}$ and $7 \%$ in the study by Shaikh. ${ }^{4}$

The data found show that no individual symptom or sign, or any combination of symptoms or signs, was sufficient to rule in a diagnosis of UTI, though some post-test probabilities (such as $25 \%$ for increased capillary refill time, no fluid intake, and supra-pubic tenderness) appear high enough to mandate urine testing and empirical treatment while awaiting culture confirmation. A number of symptoms and signs did not appear to have diagnostic value, including some that were recommended for the diagnosis of UTI by NICE ${ }^{8}$ (for example, poor feeding and vomiting). Some symptoms, signs (for example, respiratory), and proposed clinical prediction rules did reduce the probability of UTI to below $2 \%$ (given a pre-test probability of $4 \%$ ) and these may be considered low enough to rule out UTI and avoid the need to obtain urine. These are summarised in table $1 \Downarrow$.

The largest study, which included almost 16000 children, ${ }^{5}$ derived a clinical prediction rule based on a combination of 27 signs and symptoms. Results were not reported for specific thresholds, but the model was found to have an area under the receiver operating characteristic curve of 0.80 (95\% confidence interval 0.78 to 0.82 ) leading the authors to conclude that a computer assisted diagnostic decision tool based on this model could improve decision making in the emergency department.

\section{Dipstick testing}

We identified five primary studies conducted in children aged less than 5 years that assessed nitrite and leucocyte esterase dipstick testing in an emergency department setting,, ${ }^{13} 14151617$ all of which were included in our previous HTA review, ${ }^{6}$ though our published analysis was not stratified by age $<5$ years. The age stratified results presented in the web table suggest that nitrite and/or leucocyte esterase positivity are useful for identifying children in whom urine should be cultured to confirm the presence of a UTI with post-test probabilities of between $20 \%$ and $84 \%$. If both nitrite and leucocyte esterase are negative, the post-test probability ranged from $1 \%$ to $2 \%$ (based on pre-test probably of $4 \%$ to $7 \%$ ) and this may be sufficient to rule out UTI without urine culture (table 1).

\section{Urine sampling}

The NICE guidelines found "insufficient data to draw conclusions about urine collection bags and urine collection pads" and "low-level evidence that showed that the accuracy of urine collection pads was greatly improved if the pads were not used for longer than 30 minutes. ${ }^{, 8}$ We identified one study published since these recommendations that reported a sensitivity of $88 \%$ and a specificity of $80 \%$ for bag samples compared to the recommended (reference) standard of catheter samples in non-toilet trained children. ${ }^{18}$ No further studies addressing nappy pads were identified.

\section{Is ongoing research likely to provide relevant evidence?}

We searched (8 September 2011) the UK Clinical Research Network Study Portfolio (http://public.ukcrn.org.uk/search) for diagnostic studies of UTI in children and identified the Diagnosis of Urinary Tract infection in Young children (DUTY) study (www.dutystudy.org.uk) and the Epidemiology of Urinary Tract Infection (UTI) in Children with Acute Illness in Primary Care (EURICA) study. DUTY is a diagnostic cohort study designed to derive, validate, and test the efficiency of a diagnostic algorithm (that includes symptoms, signs, and dipstick urinalysis) for UTI in acutely unwell preschool children presenting to primary care. The study will also compare contamination rates between pad and clean catch urine sampling methods and is due to report at the end of 2012. EURICA is designed to estimate the prevalence of UTI in acutely unwell children aged less than 5 years presenting to primary care.

\section{What should we do in the light of the uncertainty?}

Many primary care clinicians will question the relatively high prevalence of UTI of $4 \%$ and $7 \%$ reported in the studies by $\mathrm{O}^{\prime}$ Brien $^{6}$ and Shaikh, ${ }^{4}$ since prevalences of this level might suggest more children develop complications than we currently appear to observe. There are a number of possible reasons for this high prevalence, including: (1) false positive results due to contamination; (2) false positive results due to asymptomatic bacteriuria; ${ }^{19}$ (3) poor recognition of complications due to the limitations of existing tests (such as ultrasound and dimercaptosuccinic acid (DMSA) scans to detect renal scarring); and (4) uncertainty regarding the natural history of, and the development of complications from, UTI in children.

As with many decisions about who to test in primary care, acutely unwell children can be divided into three broad groups; those who on clinical grounds almost certainly do not have a clinically important UTI (no test); those who almost certainly do (test and treat); and the group in the middle for whom there is ongoing uncertainty. Data presented here suggest we may be able to identify some children in the first group (see table 1), but until studies conducted in family physician and general practice settings report both UTI prevalence and the diagnostic value of symptoms and signs, we recommend primary care clinicians adopt a low threshold for urine testing and the use of immediate antibiotics for children testing positive for nitrites or leucocyte esterase, while awaiting culture confirmation.

As to how urine should be sampled, a clean catch approach is always best, especially after cleaning the perineum. Given the absence of clear advantage of the so called pad over bag methods in terms of the risk of contamination, carer or clinician preference and availability and costs of pad or bag should guide the method.

This is one of a series of occasional articles that highlight areas of practice where management lacks convincing supporting evidence. The series adviser is David Tovey, editor in chief, the Cochrane Library. This paper is based on a research priority identified and commissioned by the National Institute for Health Research's Health Technology 


\section{Recommendations for further research}

1. How do the presence versus absence of symptoms, signs, and abnormal dipstick urinalysis in preschool children attending primary care with an acute illness correlate with the microbiologically confirmed presence of a recognised urinary pathogen at an adequate concentration? 2. Among preschool children attending primary care with suspected UTI and in whom urine sampling is warranted, what is the effect of of nappy pads, urine bags, or clean catch samples on rates of microbiologically confirmed contamination of urine specimens? (The DUTY study attempts to address both these questions.)

Assessment programme on an important clinical uncertainty. To suggest a topic for this series, please email us at uncertainties@bmj.com. Contributors: ADH conceived the idea for the paper. PW conducted the literature review and summary. $\mathrm{ADH}, \mathrm{CCB}$, and PW wrote different sections of the initial draft and contributed to further revisions. $A D H$ is the guarantor.

Competing interests statement: All authors have completed the Unified Competing Interest form at www.icmje.org/coi_disclosure.pdf (available on request from the corresponding author) and declare: $\mathrm{ADH}, \mathrm{PW}$, and CCB are currently receiving research funding support from the National Institute for Health Research Health Technology Assessment as investigators on the DUTY study; the views expressed in this publication are those of the authors and not necessarily those of the NHS, the National Institute for Health Research or the Department of Health; none has financial relationships with any organisations that might have an interest in the submitted work in the previous 3 years.

Provenance and peer review: Commissioned; externally peer reviewed.

1 Vernon SJ, Coulthard MG, Lambert HJ, Keir MJ, Matthews JN. New renal scarring in children who at age 3 and 4 years had had normal scans with dimercaptosuccinic acid: follow up study. BMJ 1997;315:905-8.

2 Sacks SH, Verrier Jones K, Roberts R, Asscher AW, Ledingham JG. Effect of symptomless bacteriuria in childhood on subsequent pregnancy. Lancet 1987;2:991-4.

3 Shaikh N, Ewing AL, Bhatnagar S, Hoberman A. Risk of renal scarring in children with a first urinary tract infection: a systematic review. Pediatrics 2010;126:1084-91.

4 Shaikh N, Morone NE, Bost JE, Farrell MH. Prevalence of urinary tract infection in childhood: a meta-analysis. Pediatr Infect Dis J 2008;27:302-8.

5 Craig JC, Williams GJ, Jones M, Codarini M, Macaskill P, Hayen A, et al. The accuracy of clinical symptoms and signs for the diagnosis of serious bacterial infection in young febrile children: prospective cohort study of 15781 febrile illnesses. BMJ 2010;340:c1594.

6 O'Brien K, Stanton N, Edwards A, Hood K, Butler CC. Prevalence of urinary tract infection (UTI) in sequential acutely unwell children presenting in primary care: exploratory study. Scand J Prim Health Care 2011;29:19-22.
7 Coulthard MG, Vernon SJ, Lambert HJ, Matthews JNS. A nurse led education and direct access service for the management of urinary tract infections in children: prospective controlled trial. BMJ 2003;327:656

8 National Institute for Health and Clinical Excellence (NICE). Urinary tract infection in children: diagnosis, treatment and long-term management. NICE Clinical Guideline 54. August 2007. www.nice.org.uk/nicemedia/pdf/CG54NICEguideline.pdf.

9 Whiting P, Westwood M, Bojke L, Palmer S, Richardson G, Cooper J, et al. Clinical effectiveness and cost-effectiveness of tests for the diagnosis and investigation of urinary tract infection in children: a systematic review and economic model. Health Technol Assess 2006;10:1-154.

10 Shaikh N, Morone NE, Lopez J, Chianese J, Sangvai S, D'Amico F, et al. Does this child have a urinary tract infection? JAMA 2007;298:2895-904.

11 Gorelick MH, Shaw KN. Clinical decision rule to identify febrile young girls at risk for urinary tract infection. Arch Pediatr Adolesc Med 2000;154:386-90.

12 Gorelick MH, Hoberman A, Kearney D, Wald E, Shaw KN. Validation of a decision rule identifying febrile young girls at high risk for urinary tract infection. Pediatr Emerg Care 2003;19:162-64.

13 Armengol CE, Hendley JO, Schlager TA. Should we abandon standard microscopy when screening for urinary tract infections in young children? Pediatr Infect Dis J 2001;20:1176-7.

14 Dayan PS, Bennett J, Best R, Bregstein JS, Levine D, Novick MK, et al. Test characteristics of the urine Gram stain in infants $<$ or $=60$ days of age with fever. Pediatr Emerg Care 2002;18:12-4.

15 Lejeune B, Baron R, Guillois B, Mayeux D. Evaluation of a screening test for detecting urinary tract infection in newborns and infants. J Clin Pathol 1991;44:1029-30.

16 Shaw KN, McGowan KL, Gorelick MH, Schwartz JS. Screening for urinary tract infection in infants in the emergency department: which test is best? Pediatrics 1998;101:e1.

17 Shaw KN, Hexter D, McGowan KL, Schwartz JS. Clinical evaluation of a rapid screening test for urinary tract infections in children. $J$ Pediatr 1991;118:733-6.

18 Etoubleau C, Reveret M, Brouet D, Badier I, Brosset P, Fourcade L, et al. Moving from bag to catheter for urine collection in non-toilet-trained children suspected of having urinary tract infection: a paired comparison of urine cultures. J Pediatr 2009;154:803-6.

19 Wettergren B, Jodal U, Jonasson G. Epidemiology of bacteriuria during the first year of life. Acta Paediatr Scand 1985;74:925-33.

Accepted: 20 September 2011

Cite this as: BMJ 2011;343:d6316

(c) BMJ Publishing Group Ltd 2011 


\section{Table}

Table 1 | Symptoms and signs and dipstick test results helpful for ruling out urinary tract infection in children $<5$ years

\begin{tabular}{|c|c|c|c|c|c|c|c|}
\hline \multirow{2}{*}{$\begin{array}{l}\text { Clinical signs or } \\
\text { symptoms }\end{array}$} & \multirow[b]{2}{*}{ Age (years) } & \multirow[b]{2}{*}{$\begin{array}{l}\text { No of } \\
\text { studies }\end{array}$} & \multirow[b]{2}{*}{ No of children } & \multirow{2}{*}{$\begin{array}{l}\text { Prevalence of } \\
\text { sign or } \\
\text { symptom }(\%)^{*}\end{array}$} & \multirow[b]{2}{*}{$\begin{array}{l}\text { Likelihood ratio (95\% } \\
\text { CI) }\end{array}$} & \multicolumn{2}{|c|}{ Post-test probability (\%)‡ } \\
\hline & & & & & & $\begin{array}{c}\text { Based on } 4 \% \\
\text { prevalence }\end{array}$ & $\begin{array}{c}\text { Based on } 7 \% \\
\text { prevalence }\end{array}$ \\
\hline $\begin{array}{l}\leq 2 \text { of: }<12 \text { months old; white } \\
\text { race; temp } \geq 39^{\circ} \mathrm{C} \text {; no } \\
\text { apparent source of fever; } \\
\text { fever for }>48 \text { hours }\end{array}$ & $0-2$ & $2^{89}$ & 1681 & NA & $\begin{array}{c}0.15(0.05 \text { to } 0.46)^{8} ; 0.17 \\
(0.10 \text { to } 0.46)^{9}\end{array}$ & $0.6 ; 0.7$ & $1.1 ; 1.3$ \\
\hline Stridor & $0-5$ & $1^{2}$ & 15781 & 1.8 & $0.20(0.05$ to 0.81$)$ & 0.8 & 1.5 \\
\hline Audible wheeze & $0-5$ & $1^{2}$ & 15781 & 6.4 & 0.25 (0.13 to 0.48$)$ & 1.0 & 1.8 \\
\hline Circumcised males & $0-2$ & $6 \S^{7}$ & 6835 & NA & 0.33 (0.18 to 0.63$)$ & 1.4 & 2.4 \\
\hline $\begin{array}{l}\text { Temp }<39^{\circ} \mathrm{C} \text { with a } \\
\text { potential source of fever }\end{array}$ & $0-1$ & $1 \S^{7}$ & 945 & NA & $0.37(0.16$ to 0.85$)$ & 1.5 & 2.7 \\
\hline Abnormal chest sounds & $0-5$ & $1^{2}$ & 15781 & 15.7 & $0.43(0.31$ to 0.58$)$ & 1.8 & 3.1 \\
\hline Chest crackles & $0-5$ & $1^{2}$ & 15781 & 8.3 & $0.46(0.30$ to 0.70$)$ & 1.9 & 3.3 \\
\hline Age $\leq 3$ years & $0-5$ & $1^{2}$ & 15781 & 78.5 & $0.47(0.37$ to 0.61$)$ & 1.9 & 3.4 \\
\hline Did not feel hot & $0-5$ & $1^{2}$ & 15781 & 7.7 & 0.47 (0.31 to 0.73$)$ & 1.9 & 3.4 \\
\hline Breathing difficulty & $0-5$ & $1^{2}$ & 15781 & 13.7 & $0.48(0.35$ to 0.66$)$ & 2.0 & 3.5 \\
\hline \multirow{3}{*}{$\begin{array}{l}\text { Dipstick: leucocyte } \\
\text { esterase or nitrite negative }\end{array}$} & $0-12$ & $1^{11}$ & 246 & NA & $0.88(0.71$ to 1.1$)$ & 3.5 & 6.2 \\
\hline & $0-18$ & $1^{12}$ & 243 & & 0.11 (0.04 to 0.28$)$ & 0.5 & 0.8 \\
\hline & $0-24$ & $1^{14}$ & 491 & & $0.72(0.55$ to 0.94$)$ & 2.9 & 5.1 \\
\hline $\begin{array}{l}\text { Dipstick: leucocyte esterase } \\
\text { and nitrite negative }\end{array}$ & $0-48$ & $4^{10111314}$ & 4870 & NA & $0.27(0.21$ to 0.35$)$ & 1.1 & 2.0 \\
\hline
\end{tabular}

*Data on the prevalence of individual features are taken from the study by Craig et al, ${ }^{2}$ which enrolled children presenting to an emergency department with fever. Data on the prevalence of features not assessed in this study were not available. Prevalence of these features is likely to vary according to setting.

†The further the likelihood ratio is away from 1 the stronger the evidence for the absence of disease. A likelihood ratio of $<0.1$ is considered to provide strong evidence to rule out a UTI. ${ }^{17}$

‡Pre-test probabilities (prevalence) selected based on O'Brien et $\mathrm{al}^{3}(4 \%)$ and Shaikh et $\mathrm{al}^{1}(7 \%)$.

$\S$ Studies included in the systematic review by Shaikh et al. ${ }^{7}$ 